\section{INQUIRY ON CHOLERA.}

(No. VI.)

By THOMAS HUNT, Esa.

THE chief value of a provincial inquiry into the pherbmena of an epidemic, as compared with the history of its ravages in a city or large town, is derived from the superior facilities of observation presented by a small isolated district. In small towns, villages, and hamlets, where the movements of every individual are easily traced, the proof of contagion or non-contagion, as well as of the influences of local causes, is more palpable. The evidence is brought into a field of view much better adapted for observation than when seen through the mazes and mysteries of a populous and busy city. The following history of the cholera at Herne Bay in 1834, as compared with its almost total absence in 1849, supplies a stronger body of evidence as to the preventive influence of good drainage than has yet been presented, perhaps, in any published account.

Mr. Godfrey reports that Herne Bay, as a watering place, has been wholly free from cholera in the recent visitation. The only cases which occurred in the district were out of the town, in the neighbourhood of a foul ditch containing the drainage (if such it could be called) of the wretched habitations of the lowest and dirtiest of the parish. Even in this locality there were but three cases of cholera, two of which were fatal; and although diarrhœa was prevalent, there was not a single case, either of dysentery or typhus The cholera cases were females, all of one family, and Mr. Godfrey says he should think that every predisposing cause mentioned in the list was at work freely amongst them. Besides these, one case was taken on shore in a dying state from the Margate steam-boat, but the disease did not spread. So much for the sanitary condition of the Bay in 1849, a period at which the drainage of the town had been long completed, and the open, airy, and unsheltered condition of the houses, well exposed to the sea breezes, rendered it almost impossible for an epidemic to trayerse the neighbourhood. But in the year 1834 a very different state of things existed. Herne Bay was at that period an infant watering place, unfinished in every sense of the word. Arrangements had been made for its complete drainage, but had not then been carried out. The main sewer had not been constructed, but its place was supplied by an open brook or culvert, which was the natural drain of the neighbouring hills, and which, receiving the contents of the house sewers, meandered through the centre of the town, its mouth being choked with beach, and its contents stagnant and putrid, and in the highest degree offensive; its stench was perceptible on the brow of a cliff half a mile distant.

In the month of August, 1834, after a long drought, the cholera was reported to be travelling along the northern coast of Kent, from West to East. It had spent its strength at Faversham and at Whitstable, where its ravages were so dreadful, that a medical practitioner of the latter place actually deserted his post, and took to his heels. At this period a brig of coals from an uninfected port arrived at Herne Bay, and was stranded for unloading exactly at the mouth of the culvert, the wind blowing strong S.W. in the direction of the ditch, right upon the brig. At five o'clock in the morning five men began to unload the brig, breathing for three hours before breakfast the fatal breeze, and drinking pint after pint of ill-conditioned beer. At nine o'clock one of them, a healthy, sober, well-fed inhabitant of the Bay, in the prime of life, was seized suddenly with cramps, vomiting, and purging of rice-water fluid. At ten o'clock he was cold, blue, and collapsed, and at nine in the evening a corpse. The other men at work on the brig were all taken ill at the same time, some with diarrhœa, others with vomiting and cramps, but all recovered. At the same hour two children were attacked at a distant part of the town, living in a lone house to leeward of the ditch, and at a distance from it. They were ill-fed, and the house was dirty. They both died; and from this time every day numbered two or three victims. First, the ill-fed, the intemperate, and the sickly were attacked, then a very few of the healthy. The disease lurked most in underground apartments, and in the houses of laundresses, especially where the house-drains, receiving soap-suds, communicated with a privy near the house. No treatment availed. Most of the cases were fatal, and few survived twenty-four hours. Few had premonitory diarrhœea. Many were seized suddenly with awful cramps or convulsions; and a deluge of serum would forthwith gush from the bowels, and reduce them in a few minutes to a state of hopeless collapse. Intense thirst was a marked symptom. There was not a single event which tended to excite even a suspicion of the contagious nature of the disease ; and yet such was the horror of infection, that no female could be found with sufficient courage to act as a nurse, though a large sum was offered. At length two drunken men, moved by their love of brandy, (a pint per diem being allowed them by the Board of Health,) offered their services, and nursed the sick night and day for three weeks, changing and washing their linen, burying the dead, and burning their beds. Neither of these men were attacked uith cholera, nor even with diarrhoea. Almost every other inhabitant had an attack of diarrhœa, as likewise several of the visitors, only one of whom died of cholera. Consecutive fever occurred in nearly all the recovered cases; and typhus and dysentery became very common.

In three weeks from its commencement the cholera departed, and then appeared at Margate, having skirted the neighbouring villages and hamlets. From Margate it travelled to Ramsgate and Devon, remaining three weeks at each place. Every plan of treatment at that ime suggested was tried, but seldom methodically; and nothing appeared to do any good. Almost every victim was attacked at half-past one o'clock in the morning, and few survived twenty-four hours. At first the drunken were attacked, then the sickly, afterwards 
the temperate and healthy. Such was the panic excited that nearly all the visitors, and at least a third of the inhabitants, fled. Poor families might be met in the lanes riding with their furniture in a cart or waggon, not knowing whither they were going, but anxious to run any where to escape the pestilence. And yet it is remarkable that not one person appeared to take the cholera, either from contagion or from fear. Most of the victims appeared unmoved and unalarmed until the moment of seizure ; and several females were frightened into diarrhœa, and even into hysterics, but all of these escaped the cholera. One lady, who had been an invalid for years, suffering from various severe hysterical and other affections of the nervous system, not only escaped the cholera, but recovered her health and strength in the very midst of it, and retained her improved health for years. She ultimately relapsed, and suffered for another term of years, but has much improved since the visitation of last year, living in a very infected district, but wholly escaping its malign influence.

It may be some encouragement to medical men to use their influence for the purpose of promoting sanitary improvements, to relate the salutary as well as the disastrous effects of the visitation of 1834 on the town of Herne Bay. One of the medical practitioners called the attention of the commissioners of the town to the approach of the cholera before its arrival, rebuking their supineness, and exhorting them to prepare for the advance of the enemy: they received his admonition with scoffs and sneers. After the visitation had passed by, the same individual admonished the same commissioners that, if the Bay were not properly drained before the following midsummer, every newspaper in England should proclaim its pestilential condition. It was done : the commissioners believed him this time; a new sewer was constructed, arched over, and taken down to the sea, so that its mouth is washed by every tide, and every spring tide reaches to its various branches. From the summer of 1835 to the present time, Herne Bay has been one of the healthiest places in England.

26, Bedford Square, April 9, 1850.

Dr. Dix, of Long Buckby, Northamptonshire, has contributed the following short sketch of the healthy condition of that locality, as attributable to good drainage and ventilation :-

Long Buckley, Dec. 6th, 1849.

Dear Sir,-Agreeably to the request inserted in the Provincial Journal for September, 19, 1849, I beg to hand you a few observations on the subject of cholera.

. Answer to Question 1.-This town and for three or four miles round has not furnished a case of Asiatic cholera during the late or previous epidemic in 1832 . The situation of the place is elevated, and lies about the centre of the kingdom; the soil, a stiff loam and in the highest state of cultivation. The drainage is excellent. The surface undulating, with a considerable quantity of wood.
The town, which is well supplied with the purest water, contains nearly two thousand five hundred inhabitants, composed of agricultural labourers and working shoemakers, the former earning about nine or ten shillings, and the latter from twelve to fifteen, weekly. Their cottages are chiefly built of mud, but are comfortable, both as respects drainage and ventilation; and I think you will agree with me in attributing our exemption from the late scourge, as mainly caused by our locality and its attendant circumstances.

Answer to Question 13.-We have had more than the usual number of cases of diarrhoea this season, but all have recovered except two, which have become chronic; one, an old delicate woman of seventy years of age, and the other, a man with extensive hepatic disease. The plan of treatment adopted has been the administration of the cretaceous mixture, with or without laudanum, as occasion might require, and when the secretions were very faulty, the Dover's powder, with the Hydrarg. cum Cretâ, never failed to effect a cure, aided by farinaceous diet, recumbent posture, and a warm apartment.

I am, truly yours,

William Dix.

Mr. Green, of Birmingham, relates the following history. The results of the post-mortem examinations are exceedingly interesting :-

Report of the Cholera Cases occurring in the Birmingham Workhouse, in the month of October, 1849, in the form of replies to a series of queries, published in the Provincial Medical and Surgical Journal, for September 19, 1849.

1. During the epidemic of 1832 , somewhat less than thirty cases of cholera were reported in Birmingham, and about the same number, or perhaps rather more, have occurred now; on both occasions many of the cases were imported, but fewer now than at its former visit. I know of no local circumstance, either then or now, save the general salubrity of the town, which can account for this comparative exemption.

2. I have seen sixteen cases, fourteen of which were fatal.

3. The disease first appeared in the male insane wards of the workhouse, on the afternoon of October 2nd. In the course of sixty hours six cases occurred, all of which proved fatal; and within the same time there were five cases of choleraic diarrhoa (rice-water discharges), which recovered. These wards are completely insulated from, and have no communication with, the rest of the establishment. From the 7 th to the 12th three men died in another part of the establishment. One, after a few hours' illness, an old man, long an inmate of the workhouse, who was employed in the dead-room to sew up and clean the bodies after the post-mortem examinations, which he had done for all the cholera cases. He was a man of dirty and intemperate habits. The other two were brought from another part of the town. Their cases were protracted, and somewhat dubious in character, inasmuch as there was bile in their evacuations, and the collapse came on gradually, and was not well marked, but there was the same appearance, (save that 
the bladder contained urine in this case, but not in the others,) found after death as in the genuine cases. On the 11th the disease broke out in the nursery, a room on the third story, above the female insane wards, far distant from, and having no communication whatever with, that part of the establishment where the disease first appeared. Here, within three days, four cases, and four only, occurred: one, a nurse girl, who recovered, and three children, two of whom died. About the same time two men were brought from another part of the town, who died; and on the 18th the last case, also a fatal one, occurred. This was an elderly man, who had been employed to assist at the burying of the dead, and who, just before he was taken ill, had been nursing a cholera patient in Park-street. From this time there has been no other case in the workhouse, and very few in any other part of the town.

4. I cannot trace the disease to any local atmospheric impurity. The insane, who were the first attacked, are the best fed, the best lodged, and altogether the best attended to of any in the place.

5. Dysentery had been very prevalent for many weeks, but was much on the decline at the time the cholera first appeared in the workhouse, lingering only in some of the lower parts of the town. There had been diarrhœa also, but no typhus.

6. The attacks might generally be traced to some predisposing cause, rarely, if ever, happening to a thoroughly healthy subject.

7. In nearly all the cases, the collapse came on suddenly, without any, or with only short, premonitory symptoms. In the last of my own cases (the insane) a tolerably strong and healthy man, with chronic mania, about thirty years of age, was taken in the middle of the night with slight retching, and in half an hour, without either vomiting, purging, or cramp, which, however, came on afterwards, he was cold, blue, and pulseless.

8. The symptoms were those usually observed in the most malignant form of the disease. The vomiting and purging were not very profuse, and by no means proportioned to the severity of the disease. The one who had the most profuse discharges recovered. There was very little cramp ; only one suffered from it severely, and in him it was confined to the abdominal muscles. None had it in the extremities.

9. Those habits, and that diet and mode of living which tend to keep people in good health under ordinary circumstances, also protect them from this disease.

10. No answer to this.

11. The two latter parts of this query $I$ answer in the negative. The post-mortem examination of the first case developed great vascularity of the mucous coat of the ileum, whilst in the other it had a soddened look, like a washerwoman's hand, or a piece of boiled tripe. In this case the intestines were filled with a gruelly fluid, but in all the others they were empty, being merely coated with a tenacious pasty layer of mucus. In the second case the colon presented the same condition as in the first, but the small intestines had a granulated appearance, being thickly studded with semi-globular projections, about the size of mustard seeds, transparent as if containing clear lymph, and without surrounding inflammation, most distinct in the lower part of the ileum, but extending through the whole tract of the small intestines; and this same appearance was found in all but one of the cases afterwards examined, but not so strongly marked. The villi also were enlarged and elongated. In all the cases the gall-bladder contained bile, and the blood was fluid. but coagulated on exposure. All the examinations took place within eight hours after death. In one case there was a patch of ecchymosis on the heart, covering the left auricle and posterior part of left ventricle. These examinations were made with very great care by my intelligent young friend, Mr. George Blunt.

12. Our patients died, and I have therefore nothing to say of treatment.

13. The diarrhœa prevalent prior to the cholera visitation was usually amenable to the ordinary astringents, preceded occcasionally by a mild aperient, such as a blue pill and rhubarb draught. Dysentery I often combatted successfully with nitro-muriatic acid. The choleraic diarrhœa was most effectually restrained by camphor and Plumb. Diacet., of each five grains every two hours.

14. As far as my observation goes, cholera attacks those, and those only, whose constitutions are enfeebled by any means-by anxiety, by over-exertion-mental or bodily, by insufficient or improper food, by intemperance, by living in close and ill-ventilated situations, or in the neighbourhood of stagnant water or cesspools, exposed to the exhalations from decom. posing animal and vegetable matter. Remove these and all other like causes which tend to lower the standard of health, and you prevent the disease.

15. Or the disease once established, remove all persons from infected to healthy districts, and you stop its progrees.

Newhall Street, Birmingham, November 8, 1849.

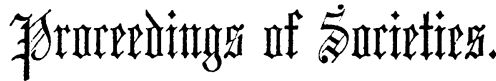

MEETING OF THE

\section{WEST SOMERSET BRANCH}

A Spectal General Meeting of the members of the West Somerset Branch of the Provincial Medical and Surgical Association was held at Giles' Castle Hotel, Taunton, on Wednesday, April 3rd, for the purpose of discussing the question of Medical Reform, in accordance with the resolutions of the Central Council of the Association, dated March 18th, 1850. Henry Alford, Esq., F.R.C.S.E., President of the Branch, in the Chair.

The following,resolutions were unanimously adopted :

1st. On the motion of Dr. Burridge, of Taunton, seconded by Mr. Gilletr, of Taunton,-

"That" this]Branch recognizes and adheres to the principles which the Association has always maintained, namely :-

1st. Uniform and sufficient qualification in every branch of medical science. 